Pacific Journal of Mathematic 


\title{
BOOLEAN ALGEBRAS OF PROJECTIONS OF FINITE MULTIPLICITY
}

\author{
S. R. FOGUEL
}

Introduction. The multiplicity theory in Banach spaces has been developed recently by Dieudonne [2] and Bade [1]. In [6] we studied the algebra of bounded operators, in a given Hilbert space, that commute with all projections of a given Boolean algebra of self adjoint projections. By using Bade's paper [1], we propose to generalize these results to Banach spaces. The notation of [1] will be used. Let $X$ be a complex Banach space. Let the Boolean algebra of projections be given as follows:

On the compact Hausdorff space $\Omega$, let a measure $E(\cdot)$ be defined for every Borel set, such that:

1. For every Borel set $\alpha, E(\alpha)$ is a projection on $X$.

2. For every $x \in X$, the vector valued set function $E(\cdot) x$ is countable additive.

3. If $\alpha$ and $\beta$ are Borel sets then

$$
E(\alpha) E(\beta)=E(\alpha \cap \beta) .
$$

4. There exists a constant $M$ such that $|E(\alpha) \leqq M|$ for every Borel set $\alpha$. 5. The Boolean algebra of projections $E(\cdot)$ is complete. (See [1] for definition of completeness.)

In [1] the space $\Omega$ was defined to be the Stone space of the Boolean algebra. In the above form it is easier to find examples. Bade's results remain true for this slightly generalized version.

Throughout the paper we assume that the Boolean algebra has uniform multiplicity $n, n<\infty$. (Definition 3.2 of [1]). Thus the following is proved in [1]:

There exist $n$ vectors $x_{1}, x_{2}, \cdots, x_{n}$ and $n$ bounded functionals $x_{1}^{*}, x_{2}^{*}, \cdots, x_{n}^{*}$ such that:

1.

$$
X=\bigvee_{i=1}^{n} s p\left(E(\alpha) x_{i}, \alpha\right. \text { a Borel set) }
$$

2. Let $x_{i}^{*} E(\cdot) x_{i}=\mu_{i}(\cdot)$. The measures $\mu_{i} i=1, \cdots, n$ are equivalent.

3. For every Borel set $e, \mu_{i}(e) \geqq 0$ and $\mu_{i}(e)=0$ and only if $E(e)=0$.

4. If $i \neq j$ then $x_{i}^{*} E(e) x_{j}=0$.

5. For every $x \in X$ there exists $n$ functions $f_{1}(\omega), \cdots, f_{n}(\omega)$ defined on $\Omega$ such that:

a. $f_{i}(\omega) \in L\left(\Omega, \mu_{i}\right)$.

b. For every Borel set $e$,

Received July 21, 1958, and in revised form January 9, 1959. 


$$
x_{i}^{*} E(e) x=\int_{e} f_{i}(\omega) \ell_{i}(d \omega) .
$$

c. Let $e_{m}=\left\{\omega \| f_{i}(\omega) \mid \leqq m, i=1, \cdots, n\right\}$

then

$$
x=\lim _{m \rightarrow \infty} \sum_{i=1}^{n} \int f_{i}(\omega) E(d \omega) x_{i} .
$$

d. The transformation $T$ from $X$ to $\sum_{i=1}^{n} L\left(\mu_{i}\right)$ given by

$$
T x=\left(\begin{array}{c}
f_{1}(\omega) \\
\dot{\cdot} \\
f_{n}(\omega)
\end{array}\right)
$$

is continuous. The functions $f_{1}(\omega), \cdots, f_{n}(\omega)$ are uniquely defined by $x$, up to sets of measure zero.

These results are proved in 5.1 and 5.2 of [1]. Instead of writing $T x=\left(\begin{array}{c}f_{1}(\omega) \\ \vdots \\ f_{n}(\omega)\end{array}\right)$ let us use the notation $x \sim\left(\begin{array}{c}f_{1}(\omega) \\ \vdots \\ f_{n}(\omega)\end{array}\right)$.

Let $\mathfrak{A}$ be the algebra of bounded operators on $X$, which commute with all the projections $E(\alpha)$. The purpose of this paper is to study $\mathscr{H}$.

\section{Representation of the Algebra $\mathfrak{2}$}

Let $A \in \mathfrak{A}$, and let

$$
A x_{i} \sim\left(\begin{array}{c}
a_{1, i}(\omega) \\
\dot{\cdot} \\
a_{n, i}(\omega)
\end{array}\right)
$$

Denote this correspondence by $A \sim\left(a_{i, j}(\omega)\right)$. The functions $a_{i, j}(\omega)$ satisfy by 5.b.

$$
x_{i}^{*} E(e) A x_{\jmath}=x_{i}^{*} A E(e) x_{\jmath}=\int_{e} a_{i, j}(\omega) \mu_{i}(d \omega)
$$

and

$$
a_{i, j}(\omega) \in L\left(\mu_{i}\right) .
$$

Equation 2.1 defines the functions $a_{i, j}(\omega)$ uuiquely (a.e.).

Now let $x \in X$ and $x \sim\left(\begin{array}{c}f_{1}(\omega) \\ \vdots \\ f_{n}(\omega)\end{array}\right)$. If $e$ is a Borel set on which the functions $f_{i}(\omega), a_{i, j}(\omega)$ are bounded then: 


$$
E(e) x=\sum_{i=1}^{n} \int_{e} f_{i}(\omega) E(d \omega) x_{i}
$$

and

$$
\begin{aligned}
A E(e) x & =E(e) A x=\sum_{i=1}^{n} \int_{e} f_{i}(\omega) E(d \omega)\left(A x_{i}\right) \\
& =\sum_{i=1}^{n} \int_{e} f_{i}(\omega) E(d \omega)\left(E(e) A x_{i}\right) .
\end{aligned}
$$

But

$$
E(e) A x_{i}=\sum_{j=1}^{n} \int_{e} a_{j, i}(\omega) E(d \omega) x_{j}
$$

Hence

$$
E(e) A x=\sum_{1 \leqq i, j \leqq n} \int_{e} f_{i}(\omega) E(d \omega)\left(\int_{e} a_{j, i}(\lambda) E(d \lambda) x_{j}\right) .
$$

From condition 3 of the introduction it follows that

$$
\begin{aligned}
E(e) A x=\sum_{1 \leqq i, j \leqq n} \int_{e} a_{j, i}(\omega) f_{i}(\omega) E(d \omega) x_{j} \\
=\sum_{j=1}^{n} \int_{e}\left(\sum_{i=1}^{n} a_{j, i}(\omega) f_{i}(\omega)\right) E(d \omega) x_{j} .
\end{aligned}
$$

Therefore

$$
x_{j}^{*} E(e) A x=\int_{e}\left(\sum_{i=1}^{n} a_{j, i}(\omega) f_{i}(\omega)\right) \mu_{j}(d \omega) .
$$

This equation means

$$
A x \sim\left(a_{i, j}(\omega)\right)\left(\begin{array}{c}
f_{1}(\omega) \\
\cdot \\
\cdot \\
f_{n}(\omega)
\end{array}\right) .
$$

REMARK. Equation 5.b. of the introduction was proved here, for only some Borel sets. But we know that

$$
A x \sim\left(\begin{array}{c}
g_{1}(\omega) \\
\cdot \\
g_{n}(\omega)
\end{array}\right)
$$

for some functions $g_{1}(\omega), \cdots, g_{n}(\omega)$. The above argument shows that

$$
\left(a_{i, j}(\omega)\right)\left(\begin{array}{c}
f_{1}(\omega) \\
\cdot \\
\dot{f_{n}}(\omega)
\end{array}\right)=\left(\begin{array}{c}
g_{1}(\omega) \\
\cdot \\
\cdot \\
g_{n}(\omega)
\end{array}\right) \text { a.e. }
$$


THEOREM 2.1. For every operator $A \in \mathfrak{A}$ there corresponds a matrix of measurable functions $a_{i, j}(\omega), 1 \leqq i, j \leqq n$, such that:

1. $a_{i, j}(\omega) \in L\left(\mu_{i}\right)$.

2. If

$$
x \sim\left(\begin{array}{c}
f_{1}(\omega) \\
\dot{\cdot} \\
\dot{\left.f_{n}(\omega)\right)}
\end{array}\right)
$$

then

$$
A x \sim\left(a_{i, j}(\omega)\right)\left(\begin{array}{c}
f_{1}(\omega) \\
\dot{\cdot} \\
\dot{f_{n}(\omega)}
\end{array}\right) .
$$

3. If a matrix of functions, $\left(b_{i, j}(\omega)\right)$, satisfies condition 2 then $a_{i, j}(\omega)=b_{i, j}(\omega)$ a.e.

The matrix of the sum or product of two operators is the sum or product of the matrices. If $A^{-1}$ exists and is bounded then

$$
A^{-1} \sim\left(a_{i, j}(\omega)\right)^{-1} .
$$

The functions $a_{i, j}(\omega)$ are determined by equation 2.1 .

Proof. The existence of a representing matrix was proved above. The other parts of the theorem follow from the uniqueness assertion given in condition 3 .

Corollary. Let $A \in \mathfrak{U}$. If $B \in \mathfrak{U}$ and $A B=I(B A=I)$ then $B A=$ $I(A B=I)$.

Proof. If $A B=I$ then

$$
\left(a_{i, j}(\omega)\right)\left(b_{i, j}(\omega)\right)=\left(\delta_{i, j}\right) \text { a.e. }
$$

Hence

$$
\left(b_{i, j}(\omega)\right)\left(a_{i, j}(\omega)\right)=\left(\delta_{i, j}\right) \text { a.e. }
$$

Thus by Theorem $2.1 B A=I$.

Theorem 2.2. Let $A_{m}, A \in \mathfrak{A}$. If the sequence $\left\{A_{m}\right\}$ converges strongly to $A$ then sequence of functions $\left\{a_{i, j}^{(m)}(\omega)\right\}$ converges in measure to $a_{i, j}(\omega)$, for each $1 \leqq i, j \leqq n$. (It does not matter with respect to what measure, because the measures are finite and equivalent). 
Conversely, the sequence $\left\{A_{m}\right\}$ converges strongly to $A$ if:

1. The sequence $\left\{a_{i, j}^{(m)}\right\}$ converges in measure to $a_{i, j}(\omega)$.

2. The sequence $\left\{\left|A_{m}\right|\right\}$ is bounded.

3. $\bigcup_{K=1}^{\infty}\left\{\omega \| a_{i, j}^{(m)}(\omega) \mid \leqq K . \quad 1 \leqq i, j \leqq n, m=1,2, \cdots\right\}=\Omega$.

Proof. If for each $x \in X$

$$
\lim _{m \rightarrow \infty} A_{m} x=A x
$$

then for every Borel set $e$

$$
\begin{aligned}
\left|\int_{e}\left(a_{i, j}^{(m)}(\omega)-a_{i, j}(\omega)\right) \mu_{i}(d \omega)\right| & \\
=\left|x_{i}^{*} E(e)\left(A_{m} x_{j}-A x_{j}\right)\right| \leqq M\left|A_{m} x_{j}-A x_{\jmath}\right| & \rightarrow 0 \\
m & \rightarrow \infty
\end{aligned}
$$

where $M$ does not depend on $e$. Thus the sequence $\left\{a_{i, j}^{(m)}(\omega)\right\}$ converges in measure to $a_{i, j}(\omega)$.

On the other hand, if conditions 1,2 and 3 are satisfied and $e$ is a Borel set, on which the functions $a_{i, j}^{(m)}(\omega)$ are uniformly bounded, then

$$
A_{m} E(e) x_{i}=\sum_{j=1}^{n} \int_{e} a_{j, i}^{(m)}(\omega) E(d \omega) x_{j}
$$

and by the Lebesque Theorem, [5] IV.10.10

$$
\lim _{m \rightarrow \infty} A_{m} E(e) x_{i}=\sum_{j=1}^{n} \int_{e} a_{1, i}(w) E(d w) x_{1} .
$$

Now, by condition 3 , the set of linear combinations of $E(e) x_{i}$, $1 \leqq i \leqq n$ and $e$ as defined above, is dense. Thus the sequence $\left\{A_{m} x\right\}$ has a limit for $x$ in a dense subset of $X$, and by condition 2 it has a limit for every $x \in X$. Let $A$ be the strong limit of $\left\{A_{m}\right\}$ then

$$
A E(e) x_{i}=\sum_{j=1}^{n} \int_{e} a_{j, l}(\omega) E(d \omega) x_{j} .
$$

Thus the matrix of $A$ is $\left(a_{i, j}(\omega)\right)$. (See Remark before Theorem 2.1).

In order to develop further the theory, let us borrow the following results from [6].

Lemma 2.1. Let $\left(a_{i, j}(\omega)\right)$ be a matrix of measurable finite functions. There exists a decomposition of the form

$$
\left(a_{i, j}(\omega)\right)=\sum_{k=1}^{n} z_{k}(\omega) \varepsilon_{k}(\omega)+N(\omega)
$$

where $z_{1}(\omega), \cdots, z_{n}(\omega)$ are measurable functions and $\varepsilon_{1}(\omega), \cdots, \varepsilon_{n}(\omega)$, $N(\omega)$ are matrices of measurable functions satisfying: 


$$
\varepsilon_{i}^{2}(\omega)=\varepsilon_{i}(\omega), \text { if } i \neq j \text { then } \varepsilon_{i}(\omega) \varepsilon_{j}(\omega)=0, \sum_{i=1}^{n} \varepsilon_{i}(\omega)=\left(\delta_{i, j}\right) .
$$

Also

$$
\varepsilon_{i}(\omega) N(\omega)=N(\omega) \varepsilon_{i}(\omega), \quad(N(\omega))^{n}=0 .
$$

Moreover, there exist $n$ Borel sets $\beta_{1}, \cdots, \beta_{n}$ whose union is $\Omega$ such that on $\beta_{i}$ the numbers $z_{1}(\omega), \cdots, z_{i}(\omega)$ are different while $z_{i+1}(\omega)=$ $\cdots=z_{n}(\omega)=0$.

The proof is given in Lemma 3.1, 3.2 and Theorem 3.1 of [6].

TheOREM 2.3. Let $A \in \mathfrak{H}$. There exists a sequence of Borel sets, $\left\{\alpha_{m}\right\}$ such that:

1. The sequence $\left\{\alpha_{m}\right\}$ increases to $\Omega$.

2. The operator $A E\left(\alpha_{m}\right)$ is spectral. (For definition of spectral operators see [3]).

Thus $A$ is a strong limit of a sequence of spectral operators.

Proof. Let $A \sim\left(a_{i, j}(\omega)\right)=\sum_{k=1}^{n} z_{k}(\omega) \varepsilon_{k}(\omega)+N(\omega)$, where the right side of the equation is defined in Lemma 2.1. Let $\alpha$ be a Borel set such that

a. On the set $\alpha$ the functions $z_{k}(\omega)$ are bounded.

b. If $\chi_{\alpha}(\omega)$ is the characteristic function of $\alpha$, then $\chi_{\gamma}(\omega) \varepsilon_{k}(\omega)$ and $\chi_{x}(\omega) N(\omega)$ are representing matrices of the operators $E_{k, \alpha}$ and $N_{\alpha}$ respectively in $\mathfrak{U}$.

Then, by Theorem 2.1,

$$
A E(\alpha)=\sum_{i=1}^{n}\left(\int_{\alpha} z_{i}(\omega) E(d \omega)\right) E_{i, \alpha}+N_{\alpha}
$$

where $E_{i, \alpha}$ are disjoint projections and $N_{x}$ is a nilpotent of order $n$ commuting with them.

Thus, for such $\alpha$, the operator $A E(\alpha)$ is spectral, and the resolution of the identity (see [3]) of $A$ restricted to $E(\alpha) X$ is

$$
\sum E\left(z_{i}^{-1}(\cdot)\right) E_{i, \alpha} \text {. }
$$

In order to prove the theorem, we have to find a sequence of Borel sets, satisfying conditions $a, b$ and 1 . Also with no loss of generality, we may study the operator $A$ on $E\left(\beta_{i}\right) X$ (Lemma 2.1). Thus we may assume that at each point $\omega$, the matrix $\left(a_{j, k}(\omega)\right)$ has exactly $i$ eigenvalues.

Define

$$
\alpha_{m}=\left\{\omega \| z_{\jmath}(\omega) \mid \leqq m \text { and }\left|z_{\jmath}(\omega)-z_{k}(\omega)\right| \geqq \frac{1}{m}, 1 \leqq k<j \leqq i\right\} .
$$

On the set $\alpha_{m}$ the matrix $\varepsilon_{1}(\omega)$ can be calculated as follows:

Let $Q(z)$ be the polynomial 


$$
Q(z)=b_{0}+b_{1} z+\cdots+b_{i(n+1)-1} z
$$

such that:

$$
\begin{gathered}
Q\left(z_{1}(\omega)\right)=1, \quad Q\left(z_{j}(\omega)\right)=0, \quad 2 \leqq j \leqq i \\
Q^{(P)}\left(z_{j}(\omega)\right)=0, \quad 1 \leqq j \leqq i, \quad 1 \leqq p \leqq n
\end{gathered}
$$

then

$$
Q\left(a_{i, j}(\omega)\right)=\varepsilon_{1}(\omega) \text { [see [4] p. 188]. }
$$

These equations have a unique solution $b_{j}=b_{j}(\omega)$, which are measurable and bounded (on $\alpha_{m}$ ) functions of $\omega$. Thus

$$
\begin{aligned}
& \chi_{\alpha_{m}}(\omega) \varepsilon_{1}(\omega) \\
& \quad=\chi_{\alpha_{m}}(\omega)\left[b_{0}(\omega)+b_{1}(\omega)\left(a_{i, j}(\omega)\right)+\cdots+b_{i(n+1)-1}\left(a_{i, j}(\omega)\right)^{i(n+1)-1}\right]
\end{aligned}
$$

and this matrix represents the operator $E_{1, m}$, in $\mathfrak{A}$, where

$$
\begin{aligned}
E_{1, m}=E\left(\alpha_{m}\right) & {\left[\int b_{0}(\omega) E(d \omega)\right.} \\
& \left.+A \int b_{1}(\omega) E(d \omega)+\cdots+A^{i(n+1)-1} \int b_{i(n+1)-1}(\omega) E(d \omega)\right] .
\end{aligned}
$$

Similarly the matrices $\chi_{\alpha_{m}}(\omega) \varepsilon_{j}(\omega)$ represent the operators $E_{j, m}$ in $\mathfrak{A}$, and by equation 2.2 the matrix $\chi_{\alpha_{m}}(\omega) N(\omega)$ represents a nilpotent of order $n, N_{m}$, in $\mathfrak{A}$ where

$$
A E\left(\alpha_{m}\right)=\sum_{j=1}^{i} E_{j, m} \int_{\alpha_{m}} z_{j}(\omega) E(d \omega)+N_{m} .
$$

CoRollary. Let $A \in \mathfrak{U}$ be a generalized nilpotent (see [3] for definition) then

$$
A^{n}=0
$$

Proof. By equation 2.3 and Theorem 8 of [3]

$$
A E\left(\alpha_{m}\right)=N_{m} \text {. }
$$

Hence for every $x \in X$

$$
E\left(\alpha_{m}\right) A^{n} x=0
$$

therefore

$$
A^{n} x=0 .
$$

Lemma 2.2. Let $A \in \mathfrak{A}$. If $A \sim\left(a_{i, j}(\omega)\right)$ and $z_{k}(\omega), k=1,2, \cdots, n$ are the functions defined in equation 2.2 then 


$$
\left|z_{k}(\omega)\right| \leqq|A| \text { a.e. }
$$

Proof. Let us assume, to the contrary, that for some $i$ and $\varepsilon>0$ the set

$$
\gamma=\left\{\omega \| z_{i}(\omega)|\geqq| A \mid+\varepsilon\right\}
$$

is not of measure zero. Let $\left\{\alpha_{m}\right\}$ be the sequence defined in Theorem 2.3 , for some $m E\left(\gamma \cap \alpha_{m}\right) \neq 0$. Now, on $\gamma \cap \alpha_{m}\left|z_{i}(\omega)\right| \geqq|A|+\varepsilon>0$ hence $\varepsilon_{i}(\omega) \neq 0$. Thus $E\left(\gamma \cap \alpha_{m}\right) E_{i, \alpha_{m}} \neq 0$, where $E_{i, \alpha_{m}}$ is defined in Theorem 2.3. If the operator $B$ is the restriction of $A$ to $E\left(\gamma \cap \alpha_{m}\right) E_{i,{ }_{m}} X$ then

$$
B=\int_{\gamma \cap \alpha_{m}} z_{i}(\omega) E(d \omega)+M
$$

where $M$ is a nilpotent. Thus, if $|\mu| \leqq|A|$ then $|\mu| \leqq\left|z_{1}(())\right|-\varepsilon$, $\omega \in \gamma \cap \alpha_{m}$, and $\mu \notin \sigma(B)$. Also, if $|\mu|>|A|$ then $|\mu|>|B|$ and $\mu \notin \sigma(B)$. This shows that $\sigma(B)$ is empty which is impossible.

Theorem 2.4. Let $\left.\left(a_{i, j}(\omega)\right)\right) \sim A \in \mathfrak{I}$. If the number $\lambda \notin \sigma(A)$ then for some $\varepsilon>0$

$$
\operatorname{dist}\left(\lambda, \sigma\left(a_{i, j}(\omega)\right)\right) \geqq \varepsilon \text { a.e. }
$$

Proof. Let $\lambda \in \rho(A)$. The matrix of $(\lambda I-A)^{-1}$ has the form

$$
\sum_{i=1}^{n}\left(\frac{\varepsilon_{i}(\omega)}{\lambda-z_{i}(\omega)}-\frac{N(\omega)}{\left(\lambda-z_{i}(\omega)\right)^{2}}+\cdots+\frac{(-N(\omega))^{n-1}}{\left(\lambda-z_{i}(\omega)\right)^{n}}\right) .
$$

Thus by Lemma 2.2

$$
\frac{1}{\operatorname{dist}\left(\lambda, \sigma\left(a_{i, j}(\omega)\right)\right)}=\max _{k} \frac{1}{\left|\lambda-z_{k}(\omega)\right|} \leqq\left|(\lambda I-A)^{-1}\right| \text { a.e } .
$$

TheOREM 2.5. Let $\left.\left(a_{i, j}(\omega)\right)\right) \sim A \in \mathfrak{A}$ and let $f(z)$ be regular in a neighborhood of $\sigma(A)$. Then the matrix $f\left(\left(a_{i, j}(\omega)\right)\right)$ exists a.e. and it is the matrix corresponding to $f(A)$.

Proof. Let $e$ be a Borel subset of $\Omega$ then

$$
x_{k}^{*} E(e) f(A) x_{j}=x_{k}^{*} E(e) \frac{1}{2 \pi i} \int_{o} f(\lambda) R(\lambda, A) x_{j} d \lambda
$$

where $C$ is a finite collection of Jordan curves surrounding $\sigma(A)$. Now $R(\lambda ; A) \sim\left(r_{k, j}(\omega, \lambda)\right)=\left(\lambda \delta_{k, j}-a_{k, j}(\omega)\right)^{-1}$ thus 


$$
\begin{aligned}
& x_{k}^{*} E(e) f(A) x_{j}=\frac{1}{2 \pi i} \int_{o} f(\lambda)\left(x_{k}^{*} E(e) R(\lambda, A) x_{j}\right) d \lambda \\
&=\frac{1}{2 \pi i} \int_{o} f(\lambda)\left[\int_{e} r_{k, j}(\omega ; \lambda) \mu_{k}(d \omega)\right] d \lambda
\end{aligned}
$$

by equation 2.1. The functions $r_{k, j}(\omega, \lambda)$ can be computed by Cramer's rule. By Theorem 2.4 and the compactness of $C$ there exists a positive constant $\delta$ such that if $\lambda \in C$ then

$$
\operatorname{dist}\left(\lambda, \sigma\left(a_{k, j}(\omega)\right)\right) \geqq \delta \text { a.e. }
$$

Now, if $e$ is a Borel set on which the functions $a_{i, j}(\omega)$ are bounded, then the functions $r_{k, j}(\omega, \lambda)$ are measurable and bounded on $e \times C$. For such Borel sets $e$, we may use Fubini's theorem to conclude that

$$
x_{k}^{*} E(e) f(A) x_{j}=\int_{e} \frac{1}{2 \pi i}\left(\int_{0} f(\lambda) r_{k, j}(\omega, \lambda) d \lambda\right) \mu_{k}(d \omega) .
$$

From this equation it follows that the components of the matrix of $f(A)$ are given by

$$
\frac{1}{2 \pi i} \int_{C} f(\lambda) r_{k, j}(\omega, \lambda) d \lambda \text { a.e. }
$$

Now by the argument of Lemma 2.1 in [6] the matrix $f\left(\left(a_{k, j}(\omega)\right)\right)$ exists a.e. and its components are, thus, given by (*).

Theorem 2.6. Let $A \in \mathfrak{A}$ be a compact operator. If $A \sim\left(a_{i, j}(\omega)\right)$ and

$$
\left(a_{i, j}(\omega)\right)=\sum_{k=1}^{n} z_{k}(\omega) \varepsilon_{k}(\omega)+N(\omega)
$$

is the decomposition given in Lemma 2.1, then there exists a sequence $\left\{\omega_{v}\right\}$, of points in $\omega$, such that:

1. $E\left(\left\{\omega_{v}\right\}\right) \neq 0$

2. $z_{k}(\omega)=0$ a.e. for $\omega \neq \omega_{v}$ $v=1,2, \cdots$

3. $\lim _{v \rightarrow \infty} z_{k}\left(\omega_{v}\right)=0$.

Proof. Let $\beta_{i}$ and $\alpha_{m}$ be the sets defined in Lemma 2.1 and Theorem 2.3. It is enough to prove the theorem for points in $\beta_{i}$, thus we assume that the matrix $\left(a_{j, k}(\omega)\right)$ has exactly $i$ eigenvalues. Define

$$
e_{m, p}=\alpha_{m} \cap\left\{\omega \| z_{k}(\omega) \mid \geqq \frac{1}{p}, k=1, \cdots, i\right\} .
$$

The operator $A$ restricted to $E\left(e_{m, p}\right) X$ is compact and, by Theorem 2.3. has a bounded inverse. Thus the space $E\left(e_{m, p}\right) X$ has a finite dimension. Therefore there exists a finite set of points, $\omega_{1}^{m, p}, \cdots, \omega_{j}^{m, p}$, such that 


$$
E\left(\left\{\omega_{k}^{m, p}\right\}\right) \neq 0
$$

and

$$
E\left(e_{m, p}-\left\{\omega_{1}^{m, p}, \cdots, \omega_{j}^{m, p}\right\}\right)=0 .
$$

By letting $m, p \rightarrow \infty$ we get a sequence $\omega_{v}$ satisfying conditions 1 and 2. In order to prove 3 , let us assume that for some $\varepsilon>0$ there are infinitely many points, $\omega_{v}$ such that

$$
\left|z_{k_{v}}\left(\omega_{v}\right)\right| \geqq \varepsilon \text {. }
$$

The operator $A$ is compact, hence $\sigma(A)$ has only zero as a limit point. By theorem $2.4 z_{k_{v}}\left(\omega_{v}\right) \in \sigma(A)$. Thus for some constant $b \neq 0$

$$
z_{k_{v}}\left(\omega_{v}\right)=b
$$

for infinitely many points, $\omega_{v}$. Let

$$
G(b, A)=\frac{1}{2 \pi i} \int_{0} R(\lambda ; A) d \lambda
$$

where $C$ is a circle around $b$ which does not contain any other point of $\sigma(A)$. The operator $G(b ; A)$ is a compact projection. The matrix of $G(b ; A)$ is, according to Theorem 2.5 ,

$$
G\left(b ;\left(a_{i, j}(\omega)\right)\right) .
$$

Thus

$$
G(b ; A) E\left(\left\{\omega_{v}\right\}\right) \neq 0
$$

whenever $z_{k_{v}}\left(\omega_{v}\right)=b$, because the matrix of the product is not zero at $\omega_{v}$. This contradicts the fact that $G(b ; A)$ is a projection into a finite dimensional space, and thus condition 3 is proved.

EXAMPLES. The following two examples are designed to show that some of the theorems, proved in [б] for Hilbert spaces, are false for Banach spaces. Notice that the examples are simble because there exist projections on

$$
\operatorname{sp}\left\{E(\alpha) x_{i}, \alpha \text { a Borel set }\right\} .
$$

1. Let $\mu$ be the Lebesque measure on $(0,1)$. Let $f$ be a monotone increasing function such that

$$
f(0)=1, \quad f(1)=\infty, \quad f \in L(0,1) .
$$

Define

$$
\mu_{1}(e)=\int_{e} f(t) \mu(d t)
$$


The Banach space $X$ will be $L_{1}(\mu) \oplus L_{1}\left(\mu_{1}\right)$. Each $x \in X$ has the form

$$
\begin{gathered}
x=\left(\begin{array}{l}
g_{1}(\omega) \\
g_{2}(\omega)
\end{array}\right) \\
|x|=\int\left|g_{1}\right| d \mu+\int\left|g_{2}\right| f d \mu .
\end{gathered}
$$

Let

$$
E(e) x=\left(\begin{array}{l}
\chi_{e}(\omega) g_{1}(\omega) \\
\chi_{e}(\omega) g_{2}(\omega)
\end{array}\right)
$$

It follows that the Boolean algebra is complete and has uniform multiplicity 2. Let

$$
\begin{gathered}
x_{1}=\left(\begin{array}{l}
1 \\
0
\end{array}\right) \quad x_{2}=\left(\begin{array}{l}
0 \\
1
\end{array}\right) \\
x_{1}^{*}\left(\begin{array}{l}
g_{1}(\omega) \\
g_{2}(\omega)
\end{array}\right)=\int g_{1} d \mu, x_{2}^{*}\left(\begin{array}{l}
g_{1}(\omega) \\
g_{2}(\omega)
\end{array}\right)=\int g_{2} d \mu .
\end{gathered}
$$

If $A \sim \mathfrak{A}$ then $A \sim\left(\begin{array}{l}a_{1,1}(\omega), a_{1,2}(\omega) \\ a_{2,1}(\omega), a_{2,2}(\omega)\end{array}\right)$ and

$$
|A| \int\left|g_{2}\right| f d \mu \geqq\left|A\left(\begin{array}{c}
0 \\
g_{1}
\end{array}\right)\right|=\left|\left(\begin{array}{c}
a_{1,2}(\omega) g_{2}(\omega) \\
a_{2,2}(\omega) g_{2}(\omega)
\end{array}\right)\right| \geqq \int\left|a_{1,2} g_{2}\right| d \mu
$$

for every $g_{2} \in L_{1}\left(\mu_{1}\right)$. Thus

$$
\int_{e}\left|a_{1,2}(\omega)\right| d \mu \leqq|A| \int_{e} f d \mu
$$

Hence $\left|a_{1,2}(\omega)\right| \leqq|A| f(\omega)$ a.e., or

$$
a_{1,2}(\omega)=b_{1,2}(\omega) f(\omega) \text { and }\left|b_{1,2}(\omega)\right| \leqq|A| .
$$

Similarly

$$
|A| \int\left|g_{1}\right| d \mu \geqq\left|A\left(\begin{array}{c}
g_{1}(\omega) \\
0
\end{array}\right)\right|=\left|\left(\begin{array}{c}
a_{1,1}(\omega) g_{1}(\omega) \\
a_{2,1}(\omega) g_{1}(\omega)
\end{array}\right)\right| \geqq \int\left|a_{2,1} g_{1}\right| f d \mu
$$

Hence

$$
\left|\alpha_{2,1}(\omega) f(\omega)\right| \leqq|A| \text { a.e. }
$$

or

$$
a_{2,1}(\omega)=\frac{b_{2,1}(\omega)}{f(\omega)} \text { and }\left|b_{2,1}(\omega)\right| \leqq|A|
$$

Every operator in $\mathfrak{A}$ is given, thus, by a matrix of the form:

$$
\left(\begin{array}{cc}
b_{1,1}(\omega), & b_{1,2}(\omega) f(\omega) \\
\frac{b_{2,1}(\omega)}{f(\omega)}, & b_{2,2}(\omega)
\end{array}\right)
$$


where the functions $b_{i, j}(\omega)$ are measurable and bounded. Also, every such matrix defines a bounded operator.

This example shows that Theorem 2.2 of [6] can not be generalized to Banach spaces:

The two topologies on $\mathfrak{A}$ given by the norms $|A|$ and

$$
\max _{i, j} \operatorname{ess} \sup _{\omega}\left|a_{i, j}(\omega)\right|
$$

are not equivalent.

2. Let $X=C_{0} \oplus l_{1}$. Every $x \in X$ has the form

$$
x=\left(x_{1}, y_{1}, x_{2}, y_{2} . \cdots, x_{n}, y_{n}, \cdots\right)
$$

where

$$
\lim _{n \rightarrow \infty} x_{n}=0,|x|=\max \left|x_{i}\right|+\sum_{i=1}^{\infty}\left|y_{i}\right| .
$$

Define

$$
E_{n}\left(x_{1}, y_{1}, \cdots, x_{n}, y_{n}, \cdots\right)=\left(0, \cdots, 0, x_{n}, y_{n}, 0 \cdots\right) .
$$

The Boolean algebra, generated by $E_{n}$, has uniform multiplicity 2 . Let the projection $F$ be defined by

$$
\begin{aligned}
F\left(x_{1}, y_{1}, \cdots, x_{n}, y_{n}, \cdots\right) & \\
& =\frac{1}{2}\left(x_{1}+y_{1}, x_{1}+y_{1}, \cdots, x_{n}+y_{n}, x_{n}+y_{n}, \cdots\right) .
\end{aligned}
$$

The projection $F$ is not bounded but $\left|F E_{n}\right|=1$. Let the operator $B$ be defined by

$$
B\left(x_{1}, y_{1}, \cdots, x_{n}, y_{n}, \cdots\right)=\left(\frac{x_{1}}{2}, \frac{y_{1}}{2}, \cdots, \frac{x_{n}}{2^{n}}, \frac{y_{n}}{2^{n}}, \cdots\right)
$$

and let $A=B F$. The operator $A$ is bounded and compact, for if $|x|=$ $\left|\left(x_{1}, y_{1}, \cdots, x_{n}, y_{n}, \cdots\right)\right| \leqq 1$ then

$$
\begin{aligned}
\mid A x & -\frac{1}{2}\left(\frac{x_{1}+y_{1}}{2}, \frac{x_{1}+y_{1}}{2}, \cdots, \frac{x_{n}+y_{n}}{2^{n}}, \frac{x_{n}+y_{n}}{2^{n}}, 0 \cdots 0 \cdots\right) \mid \\
& =\left|\frac{1}{2}\left(0, \cdots, 0, \frac{x_{n+1}+y_{n+1}}{2^{n+1}}, \frac{x_{n+1}+y_{n+1}}{2^{n+1}}, \cdots\right)\right| \\
& \leqq \frac{1}{2^{n+1}}\left[\left(\frac{\sup \left|x_{n}\right|+\sup \left|y_{n}\right|}{2}\right)\right. \\
& \left.+\sum_{i=1}^{\infty} \frac{1}{2^{n}}+\sum_{i=1}^{\infty}\left|y_{i}\right|\right] \leqq \frac{1}{2^{n+1}}(1+2+1) \rightarrow 0 .
\end{aligned}
$$


Thus $A$ is the uniform limit of compact operators. Now, $\sigma(B)=$ $\left\{\frac{1}{2^{n}}, n=1,2, \cdots\right\}$. If $0 \neq \lambda \in \sigma(A)$ then for some $x \in X, \lambda x=A x$. Hence $x=F x$ and $\lambda x=\lambda F x=B F x=B x$. Therefore

$$
\sigma(A)=\left\{0, \frac{1}{2^{n}}, n=1,2, \cdots\right\} .
$$

Let us compute $G\left(\frac{1}{2^{n}}, A\right) x$ for $x \in X$.

$$
G\left(\frac{1}{2^{n}} ; A\right) x=\sum_{k=1}^{\infty} G\left(\frac{1}{2^{n}} ; A\right) E_{k} x .
$$

Now on $E_{k} X, \sigma(A)=\left\{0, \frac{1}{2^{k}}\right\}$, hence

$$
G\left(\frac{1}{2^{n}} ; A\right) E_{k} x=0 \text { for } k \neq n
$$

and

$$
G\left(\frac{1}{2^{n}} ; A\right) E_{n} x=F E_{n} x
$$

Therefore

$$
G\left(\frac{1}{2^{n}} ; A\right) x=F E_{n} x
$$

and

$$
\sum_{v=1}^{n} G\left(\frac{1}{2^{v}} ; A\right) x=F\left(E_{1}+\cdots+E_{n}\right) x
$$

The last equation shows that $A$ is not spectral, and the preceding equation shows that Theorem 4.4 of [6] is false for Banach spaces:

There exists a compact operator $A$ in $\mathfrak{A}$ that is not spectral though the projections $G(\xi ; A)$ are uniformly bounded.

\section{REFERENCES}

1. W. G. Bade, A multiplicity theory for Boolean algebras of projections in Banach spaces, forthcoming.

2. J. Dieudonne, Sur la theorie spectrale, J. Math. Pures Appl. (9) 35 (1956), 6-10.

3. N. Dunford, Spectral operators, Pacific J. Math., 4 (1954), 321-354.

4. - Speciral theory I, Convergence to projections, Trans. Amer. Math. Soc., 54 (1934), 185-217.

5. N. Dunford, and J. Schwartz, Linear operators, forthcoming.

6. S. R. Foguel, Normal operators of finite multiplicity, forthcoming. 



\section{PACIFIC JOURNAL OF MATHEMATICS}

\section{EDITORS}

\section{David Gilbarg}

Stanford University Stanford, California

\section{R. A. Beaumont}

University of Washington

Seattle 5, Washington

\section{A. L. Whiteman}

University of Southern California Los Angeles 7, California

L. J. Paige

University of California

Los Angeles 24, California

\section{ASSOCIATE EDITORS}

E. F. BECKENBACH
C. E. BURGESS
E. HEWITT
A. HORN

A. HORN

\author{
V. GANAPATHY IYER \\ R. D. JAMES \\ M. S. KNEBELMAN \\ L. NACHBIN
}

I. NIVEN

T. G. OSTROM

H. L. ROYDEN

M. M. SCHIFFER
E. G. STRAUS

G. SZEKERES

F. WOLF

K. YOSIDA

\section{SUPPORTING INSTITUTIONS}

\author{
UNIVERSITY OF BRITISH COLUMBIA \\ CALIFORNIA INSTITUTE OF TECHNOLOGY \\ UNIVERSITY OF CALIFORNIA \\ MONTANA STATE UNIVERSITY \\ UNIVERSITY OF NEVADA \\ OREGON STATE COLLEGE \\ UNIVERSITY OF OREGON \\ OSAKA UNIVERSITY \\ UNIVERSITY OF SOUTHERN CALIFORNIA
}

\author{
STANFORD UNIVERSITY \\ UNIVERSITY OF TOKYO \\ UNIVERSITY OF UTAH \\ WASHINGTON STATE COLLEGE \\ UNIVERSITY OF WASHINGTON \\ * * * * \\ AMERICAN MATHEMATICAL SOCIETY \\ CALIFORNIA RESEARCH CORPORATION \\ HUGHES AIRCRAFT COMPANY \\ SPACE TECHNOLOGY LABORATORIES
}

Mathematical papers intended for publication in the Pacific Journal of Mathematics should be typewritten (double spaced), and the author should keep a complete copy. Manuscripts may be sent to any one of the four editors. All other communications to the editors should be addressed to the managing editor, L. J. Paige at the University of California, Los Angeles 24, California.

50 reprints per author of each article are furnished free of charge; additional copies may be obtained at cost in multiples of 50 .

The Pacific Journal of Mathematics is published quarterly, in March, June, September, and December. The price per volume (4 numbers) is $\$ 12.00$; single issues, $\$ 3.50$. Back numbers are available. Special price to individual faculty members of supporting institutions and to individual members of the American Mathematical Society: $\$ 4.00$ per volume; single issues, $\$ 1.25$.

Subscriptions, orders for back numbers, and changes of address should be sent to Pacific Journal of Mathematics, 2120 Oxford Street, Berkeley 4, California.

Printed at Kokusai Bunken Insatsusha (International Academic Printing Co., Ltd.), No. 6, 2-chome, Fujimi-cho, Chiyoda-ku, Tokyo, Japan.

PUBLISHED BY PACIFIC IOURNAL OF MATHEMATICS, A NON-PROFIT CORPORATION

The Supporting Institutions listed above contribute to the cost of publication of this Journal, but they are not owners or publishers and have no responsibility for its content or policies. 


\section{Pacific Journal of Mathematics}

\section{Vol. 9, No. $3 \quad$ July, 1959}

Errett Albert Bishop, A minimal boundary for function algebras . . . . . . . . . . . . 629

John W. Brace, The topology of almost uniform convergence . . . . . . . . . . . . 643

Cecil Edmund Burgess, Chainable continua and indecomposability .......... 653

L. Carlitz, Multiplication formulas for products of Bernoulli and Euler

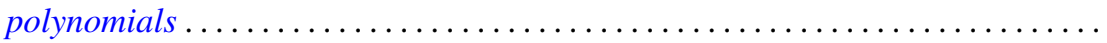

Eckford Cohen, A class of residue systems (mod $r$ ) and related arithmetical

functions. II. Higher dimensional analogues ....................

Shaul Foguel, Boolean algebras of projections of finite multiplicity . . . . . . . . . .

Richard Robinson Goldberg, Averages of Fourier coefficients .................

Seymour Goldberg, Ranges and inverses of perturbed linear operators .

Philip Hartman, On functions representable as a difference of convex functions ....

Milton Vernon Johns, Jr. and Ronald Pyke, On conditional expectation and

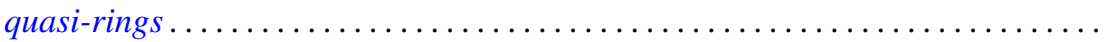

Robert Jacob Koch, Arcs in partially ordered spaces ....................

Gregers Louis Krabbe, A space of multipliers of type $L^{p}(-\infty, \infty) \ldots \ldots \ldots \ldots$

John W. Lamperti and Patrick Colonel Suppes, Chains of infinite order and their

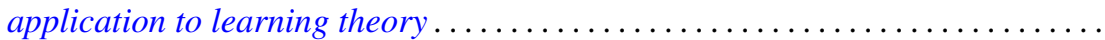

Edith Hirsch Luchins, On radicals and continuity of homomorphisms into Banach

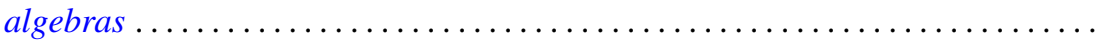

T. M. MacRobert, Multiplication formulae for the E-functions functions of their parameters.

Michael Bahir Maschler, Classes of minimal and representative domains and their kernel functions.

William Schumacher Massey, On the imbeddability of the real projective spaces in Euclidean space.

Thomas Wilson Mullikin, Semi-groups of class $\left(C_{0}\right)$ in $L_{p}$ determined by parabolic differential equations

Steven Orey, Recurrent Markov chains

Ernest Tilden Parker, On quadruply transitive groups ........ . .

Calvin R. Putnam, On Toeplitz matrices, absolute continuity, and unitary

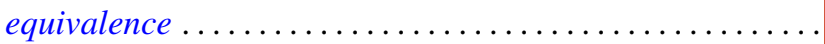

Helmut Heinrich Schaefer, On nonlinear positive operators.

Robert Seall and Marion Wetzel, Some connections between continued fractions and convex sets

Robert Steinberg, Variations on a theme of Chevalley

Olga Taussky and Hans Zassenhaus, On the similarity transformation between a

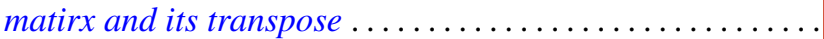

Emery Thomas, The suspension of the generalized Pontrjagin cohomology

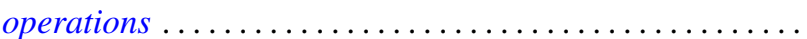

Joseph L. Ullman, On Tchebycheff polynomials ..................... 913

Richard Steven Varga, Orderings of the successive overrelaxation scheme ........ 925

Orlando Eugenio Villamayor, Sr., On weak dimension of algebras . 